\title{
Model analysis of forest thinning impacts on the water resources during hydrological drought periods
}

\author{
Hiroki Momiyama ${ }^{1}$, Tomo'omi Kumagai ${ }^{1}$, and Tomohiro Egusa ${ }^{1}$ \\ ${ }^{1}$ The University of Tokyo
}

April 5, 2021

\begin{abstract}
In Japan, there has recently been an increasing call for forest thinning to conserve water resources from forested mountain catchments in terms of runoff during prolonged drought periods of the year. How their water balance and the resultant runoff are altered by forest thinning is examined using a combination of 8-year hydrological observations, 100-year meteorological data generator output, and a semi-process-based rainfall-runoff model. The rainfall-runoff model is developed based on TOPMODEL assuming that forest thinning has an impact on runoff primarily through an alteration in canopy interception. The main novelty in this analysis is that the availability of the generated 100-year meteorological data allows the investigations of the forest thinning impacts on mountain catchment water resources under the most severer drought conditions. The model is validated against runoff observations conducted at a forested mountain catchment in the Kanto region of Japan for the period $2010-2017$. It is demonstrated that the model reproduces temporal variations in runoff and evapotranspiration at inter- and intra-annual time scales, resulting in well reproducing the observed flow duration curves. On the basis of projected flow duration curves for the 100-year, despite the large increase in an annual total runoff with ordinary intensifying thinning, low flow rates, i.e., water resources from the catchment in the drought period in the year, in both normal and drought years were impacted by the forest thinning to a lesser extent. Higher catchment water retention capacity appreciably enhanced the forest thinning effect on increasing available water resources.
\end{abstract}

\section{Hosted file}

Main Text File.pdf available at https://authorea.com/users/405840/articles/516686-modelanalysis-of-forest-thinning-impacts-on-the-water-resources-during-hydrological-droughtperiods 
figures/Fig1/Fig1-eps-converted-to.pdf 
figures/Fig2/Fig2-eps-converted-to.pdf 
figures/Fig3/Fig3-eps-converted-to.pdf 
figures/Fig4/Fig4-eps-converted-to.pdf 
figures/Fig5/Fig5-eps-converted-to.pdf 
figures/Fig6/Fig6-eps-converted-to.pdf 
figures/Fig7/Fig7-eps-converted-to.pdf 